- Describes a longitudinal observational study carried out in a primary care setting.

- Eradication of periodontal disease through dental clearance had a significant effect on CRP (a vascular marker of cardiovascular risk).

- Further larger multi-centre studies are required to determine the relationship between periodontal disease and cardiovascular risk.

\title{
Change in cardiovascular risk status after dental clearance
}

\author{
J. S. Ellis, ${ }^{1}$ P. A. Averley, ${ }_{1}^{2}$ P. M. Preshaw ${ }_{1}{ }^{\text {J. G. Steele, }}{ }^{4}$ R. A. Seymour ${ }^{5}$ and J. M. Thomason ${ }^{6}$
}

There is considerable debate over the relationship between periodontal and cardiovascular disease. ${ }^{1}$ It has been postulated that inflammatory mediators prevalent in periodontal disease may impact on atheroma formation and the thrombotic process. ${ }^{2}$ In cross-sectional, observational studies, periodontitis is associated with elevated C-reactive protein (CRP), hyperfibrinogenaemia and moderate leukocytosis. ${ }^{3-6}$ CRP levels have also been shown to decrease following periodontal therapy. ${ }^{\text {CRP }}$ is a reliable marker of the acute phase reaction to infections and/or inflammation and is a powerful predictor of future coronary events..$^{-11}$

The aim of this prospective, longitudinal observational study was to test the hypothesis that eradicating periodontal disease by dental clearance would decrease serum CRP levels. Participants were recruited from a primary dental care centre, where they had been referred for dental clearance (minimum of four teeth) for treatment of advanced periodontal disease (ie clinical cases in which the dentition could be described as terminal as a result of advanced periodontal disease characterised by extensive loss of attachment and alveolar bone loss). A full medical history was taken to exclude patients with systemic inflammatory

\footnotetext{
Senior Lecturer in Restorative Dentistry, ${ }^{2 *}$ General Dental Practitioner, ${ }^{3}$ Senior Lecturer in Restorative Dentistry, ${ }^{4}$ Professor of Oral Health Services Research, ${ }^{5}$ Professor of Restorative Dentistry, ${ }^{6}$ Professor of Prosthodontics and Oral Rehabilitation, School of Dental Sciences, University of Newcastle upon Tyne, Framlington Place, NE2 4BW

${ }^{*}$ Correspondence to: Dr Paul Averley

Email: paul@averley.com
}

\section{Refereed Paper}

Accepted 8 December 2006

DOI: $10.1038 /$ bdj.2007.373

${ }^{\circ}$ British Dental Journal 2007; 202: 543-544 disease. All patients gave informed written consent for the study which had received appropriate ethical approval.

Ten millilitres of venous blood was taken prior to the clearance. All the remaining teeth were extracted and the patients were subsequently fitted with complete dentures. Twelve weeks after clearance a further blood sample was taken. Blood samples were taken at the same time of day to minimise circadian variations and were processed and stored at $-70^{\circ} \mathrm{C}$ until analysis using standardised modular analytical technology (Tina-quant CRP, Roche, Lewes, UK).

Thirty-nine subjects completed the study (19 males). The mean age was 51 years (range 28-81 years). Prior to clearance subjects had between six and 27 teeth remaining (mean 14.7). The mean whole mouth mean probing depth was 3.5 $\mathrm{mm}$ (range of means 1.4-6.0 mm, \pm 1.05 ). All subjects had at least one sextant with a BPE score of 4, and the majority (85\%) had $50 \%$ or more horizontal bone loss. Sixty-four percent were current smokers and $13 \%$ had quit smoking within the last three months. The mean body mass index (BMI) was 28.2 (range 18.4-51.0), with 16 of the 39 subjects (41\%) being obese (BMI > 30.) The mean systolic BP was $134 \mathrm{mmHg}$ (range 104-163 $\mathrm{mmHg}$ ). Twenty-two of the 39 (56\%) were hypertensive (systolic BP > $140 \mathrm{mmHg}$ ).

CRP values were used to categorise patients as being at high, average or low risk of future coronary events. ${ }^{9}$ At baseline $46 \%$ of the subjects were classified as high risk (CRP > $3.0 \mathrm{mg} / \mathrm{l}$ ), 49\% were of average risk (CRP 1.0-3.0 mg/l) and 5\% were low risk (CRP $<1 \mathrm{mg} / \mathrm{l}$ ). After clearance, $26 \%$ of patients remained at high risk, 51\% were of average risk, and 23\% were classified as low risk. There was a significant change in the distribution of patients in each risk category following dental clearance $\left(\chi^{2}=6.766, \mathrm{p}=0.034\right)$.

Mean (sd) CRP values are shown in Table 1 . The results suggest that eradication of periodontal disease by dental clearance had a significant effect on serum CRP levels. For $61 \%$ of the subjects initially categorised as high risk, this resulted in a change to average or low category of risk (11/18). No major changes in smoking habits, diet or 


\begin{tabular}{|c|c|c|}
\hline & Baseline & Post-clearance \\
\hline $\mathrm{N}$ of subjects in high risk category (CRP > $3.0 \mathrm{mg} / \mathrm{l}$ ) & 18 & 10 \\
\hline $\mathrm{N}$ of subjects in average risk category (CRP $1.0-3.0 \mathrm{mg} / \mathrm{l}$ ) & 19 & 20 \\
\hline $\mathrm{N}$ of subjects in low risk category (CRP $<1.0 \mathrm{mg} / \mathrm{l}$ ) & 2 & 9 \\
\hline $\begin{array}{l}\text { Mean } \pm \text { SD serum CRP }(\mathrm{mg} / \mathrm{L}) \\
\text { (range) }\end{array}$ & $\begin{array}{l}3.58 \pm 2.18 \\
(0.2-10.2)\end{array}$ & $\begin{array}{l}2.35 \pm 1.45 \\
(0.2-7.1)\end{array}$ \\
\hline
\end{tabular}

medical health were noted between baseline and post-clearance, although it is not possible to rule out some dietary change as a result of extractions and adaptation to dentures.

This study confirms the findings of Taylor et al. which demonstrated a reduction in CRP levels following dental clearance of teeth with advanced periodontal disease. ${ }^{12}$ The study supports the findings of previous observational and interventional studies which suggested that periodontal inflammation affects systemic inflammatory status and that reducing the inflammatory load by eradicating periodontal disease can impact on serum inflammatory markers.

The authors recognise that this study has some limitations as it was not designed to control for confounding factors such as smoking, increased BMI and elevated systolic BP. Furthermore, it was not possible to include a control group, which would have required identifying and monitoring patients with comparable severe periodontal disease over three months, but without providing treatment - a situation which would be ethically unacceptable.
Notwithstanding these limitations, it is clear that dental clearance resulted in an apparent alteration of subjects' risk status for future coronary events, as represented by a decrease in serum CRP. Care needs to be taken in interpreting these findings in a clinical sense. This is an observational study based on a sample of people for whom a clinical decision to remove the remaining teeth had already been made, giving us the opportunity to see the effect of removing all of the infected teeth on CRP levels. Reduction in CRP was not a therapeutic goal in itself and neither was tooth removal an experimental intervention. At this stage, it would be inappropriate to make any assumptions about the links between periodontal disease and cardiovascular risks, based on the findings of this study alone. However, in the light of these findings and others, it does seem likely that periodontal inflammation may have a measurable systemic impact.

This, and similar studies, have strengthened the argument that periodontal inflammation may influence systemic inflammatory status. Clearly, larger multi-centre studies involving significant numbers of fully characterised patients are required to explore this relationship further.

1. Meurman J H, Sanz M, Janket S. Oral health atherosclerosis, and cardiovascular disease. Crit Rev Oral Biol Med 2004; 15: 403-413.

2. Offenbacher S, Madianos P N, Champagne C M E et al. Periodontitis-atherosclerosis syndrome: an expanded model of pathogenesis. J Periodont Res 1999; 34: 346-352.

3. Kweider M, Lowe G D, Murray G D et al. Dental disease, fibrinogen and white cell count; links with myocardial infarction? Scot Med J 1993; 38: 73-74.

4. Loos B G, Craandijk J, Hoek F J et al. Elevation of systemic markers related to cardiovascular diseases in the peripheral blood of peridontitis patients. J Periodontol 2000; 71: 1528-1534.

5. Slade G D, Offenbacher S, Beck J D et al. Acutephase inflammatory response to periodontal disease in the US population. J Dent Res 2000; 79: 49-57.

6. Noack B, Genco R J, Trevisan M et al. Periodontal infections contribute to elevated systemic C-reactive protein level. J Periodontol 2001; 72: 1221-1227.

7. D'Aiuto F, Parkar M, Andreou G et al. Periodontitis and systemic inflammation: control of the local infection is associated with a reduction in serum inflammatory markers. J Dent Res 2004; 83: 156-160.

8. Koenig W. C-reactive protein and cardiovascular risk: has the time come for screening the general population? Clinical Chemistry 2001; 47: 9-10.

9. Pearson T A, Mensah G A, Alexander R W et al. Markers of inflammation and cardiovascular disease: application to clinical and public health practice: a statement for healthcare professionals from the Centres for Disease Control and prevention and the American Heart Association. Circulation 2003; 107: 499-511.

10. Rossi E, Biasucci L M, Citterio F et al. Risk of myocardial infarction and angina in patients with severe peripheral vascular disease: predictive role of $\mathrm{C}$ reactive protein. Circulation 2002; 105: 800-803.

11. Albert C M, Ma J, Rifai N et al. Prospective study of C-reactive protein, homocysteine, and plasma lipids as predictors of sudden cardiac death. Circulation 2002; 105: 2595-2599.

12. Taylor B A, Tofler G H, Carey H M R et al. Fullmouth tooth extraction lowers systemic inflammatory and thrombotic markers of cardiovascular risk. J Dent Res 2006; 85: 74-78. 